\title{
Salicylate prevents hepatic insulin resistance caused by short-term elevation of free fatty acids in vivo
}

\author{
Edward Park', Victor Wong ${ }^{1}$, Xinyu Guan ${ }^{1}$, Andrei I Oprescu ${ }^{2}$ and Adria Giacca ${ }^{1,2,3}$ \\ ${ }^{1}$ Department of Physiology, ${ }^{2}$ Institute of Medical Science and ${ }^{3}$ Department of Medicine, University of Toronto, 1 King's College Circle, Toronto, Ontario, \\ M5S 1A8, Canada \\ (Correspondence should be addressed to A Giacca; Email: adria.giacca@utoronto.ca)
}

\begin{abstract}
Recent evidence indicates that inflammatory pathways are causally involved in insulin resistance. In particular, I $\mathrm{B} \alpha$ kinase $\beta$ (IKK $\beta$ ), which can impair insulin signaling directly via serine phosphorylation of insulin receptor substrates (IRS) and/or indirectly via induction of transcription of pro-inflammatory mediators, has been implicated in free fatty acid (FFA)-induced insulin resistance in skeletal muscle. However, it is unclear whether liver IKK $\beta$ activation plays a causal role in hepatic insulin resistance caused by acutely elevated FFA. In the present study, we wished to test the hypothesis that sodium salicylate, which inhibits IKK $\beta$, prevents hepatic insulin resistance caused by short-term elevation of FFA. To do this, overnight-fasted Wistar rats were subject to 7-h i.v. infusion of either saline or Intralipid plus $20 \mathrm{U} / \mathrm{ml}$ heparin $(\mathrm{IH}$; triglyceride emulsion that elevates FFA levels in vivo) with or without salicylate. Hyperinsulinemic-
\end{abstract}

euglycemic clamp with tracer infusion was performed to assess insulin-induced stimulation of peripheral glucose utilization and suppression of endogenous glucose production (EGP). Infusion of IH markedly decreased $(P<0 \cdot 05)$ insulin-induced stimulation of peripheral glucose utilization and suppression of EGP, which were completely prevented by salicylate co-infusion. Furthermore, salicylate reversed IH-induced 1) decrease in IKB $\alpha$ content; 2) increase in serine phosphorylation of IRS-1 (Ser 307) and IRS-2 (Ser 233); 3) decrease in tyrosine phosphorylation of IRS-1 and IRS-2; and 4) decrease in serine 473-phosphorylated Akt in the liver. These results demonstrate that inhibition of IKK $\beta$ prevents FFA-induced impairment of hepatic insulin signaling, thus implicating IKK $\beta$ as a causal mediator of hepatic insulin resistance caused by acutely elevated plasma FFA.

Journal of Endocrinology (2007) 195, 323-331

\section{Introduction}

Numerous studies have established a close relationship between obesity, insulin resistance, and type 2 diabetes. This link is attributed to greater release of various adipocyte products, such as cytokines, resistin, and free fatty acids (FFAs), from the expanded adipose tissue in obese individuals. In particular, elevated circulating levels of FFA cause insulin resistance in both animals and humans (Roden et al. 1996, Boden et al. 2001, Yuan et al. 2001, Lam et al. 2002, Kim et al. 2004b). However, precise mechanisms by which FFAs impair insulin action in the liver and peripheral tissues are incompletely understood.

Recent studies have demonstrated that FFA cause insulin resistance in the skeletal muscle mainly via inhibition of tyrosine phosphorylation of insulin receptor substrate (IRS)-1 (Kim et al. 2001, 2004b, Yu et al. 2002), which is a critical step in insulin signal transduction. This process is likely mediated by the phosphorylation of serine residues on IRS-1 by certain serine kinases, such as protein kinase $\mathrm{C}$ (PKC), inhibitor of I $\kappa \mathrm{B} \alpha$ kinase $\beta$ (IKK $\beta$ ), and $c$-Jun $\mathrm{NH}_{2}$-terminal kinase 1 (JNK 1). Shulman (Kim et al. 2001, 2004b, Yu et al. 2002) and others (Itani et al. 2000, 2002, Yuan et al. 2001, Boden et al. 2005) have implicated accumulation of intramyocellular lipid metabolites (e.g., diacylglycerol, long-chain fatty acyl CoA) and activation of serine kinases PKC (isoforms $\beta$ and $\delta$ in humans, and $\varepsilon$ and $\theta$ in rodents) and IKK $\beta$ as potentially causal events in the pathway of FFA-induced insulin resistance in skeletal muscle. In particular, it has been shown that mice lacking PKC- $\theta$ are protected from insulin resistance caused by a short-term lipid infusion (Kim et al. 2004b). Furthermore, treatment with high-dose sodium salicylate, an IKK $\beta$ inhibitor, or IKK $\beta$-deficiency prevents fat-induced insulin resistance in rodent skeletal muscle (Kim et al. 2001).

Recently, treatment of primary mouse hepatocytes with saturated fatty acids was found to activate JNK in association with increased IRS-1 serine 307 phosphorylation and decreased insulin-stimulated Akt activation, which were absent in hepatocytes isolated from $\mathrm{JNK}^{-/-}$mice (Solinas et al. 2006). However, potentially causal roles of serine kinases PKC, IKK $\beta$, and JNK1 in FFA-induced hepatic insulin resistance have not been extensively investigated in in vivo models. Our laboratory has previously established an association between $\mathrm{PKC}-\delta$ membrane translocation, a 
marker of its activation, and FFA-induced hepatic insulin resistance (Lam et al. 2002). This association has recently been confirmed by Boden et al. (2005), who, in the same study, also linked hepatic IKK $\beta$ activation with FFA-induced hepatic insulin resistance. However, it has not been clearly shown whether IKK $\beta$ causes hepatic insulin resistance induced by short-term elevation of circulating FFA. While Arkan et al. (2005) have demonstrated that hepatocyte-specific IKK $\beta$ knockout mice are protected from hepatic insulin resistance caused by high-fat feeding or genetically induced obesity, both of these models exhibit chronically elevated FFA levels, which may cause insulin resistance via a different mechanism than short-term FFA elevation. Thus, in the present study, we wished to test the hypothesis that IKK $\beta$ activation is causally involved in the mechanism of hepatic insulin resistance induced by acute FFA elevation. To do this, we used a rat model of short-term (7 h) i.v. lipid infusion with or without co-infusion of sodium salicylate to examine whether inhibition of IKK $\beta$ results in restoration of hepatic insulin action via prevention of FFA-induced impairment of hepatic insulin signaling.

\section{Materials and Methods}

\section{Animal models}

Female Wistar rats (Charles River, Quebec, Canada) weighing 250-300 g were used for experiments. The rats were housed in the University of Toronto's Department of Comparative Medicine. They were exposed to a $12 \mathrm{~h}$ light:12 h darkness cycle and were fed rat chow (Teklad Global \# 2018; Harland Teklad Global Diets, Madison, WI, USA) and water ad libitum. The Animal Care Committee of the University of Toronto approved all procedures.

\section{Surgery}

After 3-5 days of adaptation to the facility, rats were anesthetized with isoflurane, and indwelling catheters were inserted into the right internal jugular vein for infusion and the left carotid artery for blood sampling, as previously described (Lam et al. 2002). Briefly, polyethylene (PE) catheters (PE-50; Cay Adams, Boston, MA, USA), each extended with a segment of silastic tubing (length $3 \mathrm{~cm}$ and $0.58 \mathrm{~mm}$ in internal diameter; Dow Corning, Midland, MI, USA), were used. The venous catheter was inserted to the level of the right atrium and the arterial catheter was advanced to the level of the aortic arch. Both catheters were tunneled subcutaneously and exteriorized. The catheters were filled with a mixture of $60 \%$ polyvinylpyrrolidone and heparin $(1000 \mathrm{U} / \mathrm{ml})$ to maintain patency and were closed with a metal pin. The rats were allowed for a minimum of 3 days to recover from the surgery before experiments.

\section{Experimental design}

After overnight fasting (10-12 h), the rats ( $n=6-8$ /group) were subject to a 7-h i.v. infusion of either saline (SAL), Intralipid plus heparin (IH; 20\% Intralipid plus $20 \mathrm{U} / \mathrm{ml}$ heparin at $5.5 \mu \mathrm{l} / \mathrm{min}$ ), IH plus sodium salicylate (SS; $7 \mathrm{mg} / \mathrm{kg}$ bolus plus $0.117 \mathrm{mg} / \mathrm{kg}$ per min), or sodium salicylate alone. The dose of sodium salicylate (Sigma-Aldrich) used in the study was derived from a previous in vivo study by Kim et al. (2001) in which SS treatment was shown to prevent FFA-induced insulin resistance in skeletal muscle. After $3 \mathrm{~h}$ of infusion, $\left[3-{ }^{3} \mathrm{H}\right]$ glucose (Perkin-Elmer, Boston, MA, USA) was initiated $(8 \mu \mathrm{Ci}$ bolus followed by constant infusion at $0 \cdot 15 \mu \mathrm{Ci} / \mathrm{min}$ ) to assess peripheral glucose utilization and endogenous glucose production (EGP). Hyperinsulinemic-euglycemic clamp was performed with tracer infusion during the last $2 \mathrm{~h}$ of the $7-\mathrm{h}$ infusion period to assess hepatic and peripheral insulin sensitivity. During 30 min preceding the clamp ('basal period'), measurements were taken at 10-min interval for plasma glucose, insulin, FFA, and $\left[3-{ }^{3} \mathrm{H}\right]$ glucose-specific activity. At the onset of the clamp, an infusion of porcine insulin at $5 \mathrm{mU} / \mathrm{kg}$ per min, resulting in plasma insulin levels in the postprandial range, was initiated. To maintain euglycemia during insulin infusion, a variable infusion of $20 \%$ glucose was given through the jugular catheter and adjusted according to glycemic determinations every $5 \mathrm{~min}$. The glucose infusate was radiolabeled with $48 \mu \mathrm{Ci} / \mathrm{g}\left[3-{ }^{3} \mathrm{H}\right]$ glucose to maintain plasma glucose-specific activity constant. The total blood volume withdrawn was $\sim 3.8 \mathrm{ml}$. After plasma separation, red blood cells were diluted at $1: 1$ ratio in heparinized saline $(4 \mathrm{U} / \mathrm{ml})$ and re-infused into the rats. At the end of the experiments, the rats were anesthetized with i.v. administration of ketamine:xylazine: acepromazine cocktail $(87: 1 \cdot 7: 0 \cdot 4 \mathrm{mg} / \mathrm{ml})$, immediately after which liver, soleus muscle, and white adipose tissue samples were freeze clamped with pre-cooled aluminum tongs, while infusions were maintained through the jugular vein.

\section{Plasma assays}

Plasma glucose was measured with a Beckman Glucose Analyzer II (Beckman, Fullerton, CA, USA). Plasma radioactivity from $\left[3-{ }^{3} \mathrm{H}\right]$ glucose was determined after deproteinization with $\mathrm{Ba}(\mathrm{OH})_{2}$ and $\mathrm{ZnSO}_{4}$, and subsequent evaporation to dryness. Aliquots of the $\left[3-{ }^{3} \mathrm{H}\right]$ glucose and of the tritiated glucose infusate were assayed together with the plasma samples (Lam et al. 2002). Insulin levels in plasma were determined by RIAs using kits specific for rat insulin (but with 100\% cross-reactivity with porcine insulin used for infusion), as previously described (Lam et al. 2002). Plasma FFA levels were measured using a colorimetric kit from Wako Industrials (Richmond, VA, USA), as previously described (Lam et al. 2002).

\section{Immunoprecipitation and western blot analysis}

Liver samples $(150 \mathrm{mg}$ ) were homogenized by hand-held glass homogenizer in buffer A (50 mM Tris- $\mathrm{HCl}(\mathrm{pH} 7 \cdot 5) ; 10 \mathrm{mM}$ 
EGTA; $2 \mathrm{mM}$ EDTA; $1 \mathrm{mM} \mathrm{NaHCO}$; $5 \mathrm{mM} \mathrm{MgCl}_{2}$; $1 \mathrm{mM} \mathrm{Na} \mathrm{VO}_{4} ; 1 \mathrm{mM} \mathrm{NaF} ; 1 \mu \mathrm{g} / \mathrm{ml}$ aprotinin, leupeptin, and pepstatin; $0 \cdot 1 \mathrm{mM}$ phenylmethylsulfonyl fluoride; and $1 \mu \mathrm{M}$ microcystin). The homogenates were centrifuged at $100000 \mathrm{~g}$ for $1 \mathrm{~h}$ at $4{ }^{\circ} \mathrm{C}$, and the supernatants were retained as the cytosolic fraction. The pellet was resuspended in buffer B (buffer A $+1 \%$ Triton X-100), homogenized by passing through a 23-gauge needle thrice, incubated for $15 \mathrm{~min}$ on ice, and centrifuged at $100000 \mathrm{~g}$ for $1 \mathrm{~h}$ at $4{ }^{\circ} \mathrm{C}$. The supernatant provided the solubilized membrane fraction. The purity of the cytosolic and membrane fractions was previously assessed by assaying glucose-6-phosphate dehydrogenase (Sigma) and $5^{\prime}$-nucleotidase activities (Sigma) respectively (Lam et al. 2002). The results showed that the index of purity of both fractions were $>90 \%$. Homogenization of muscle (Wong et al. 2006) and fat (Beard et al. 2006) samples was performed as described previously. The protein concentration in all samples was determined by the detergent-compatible modified Lowry microassay, using a standardized assay kit.

Fifty micrograms of protein in liver, muscle, or fat samples were mixed with equal volumes of $3 \times$ sample-loading buffer (6.86 $\mathrm{M}$ urea, $4 \cdot 29 \%$ SDS, $300 \mathrm{mM}$ dithiothreitol, and $43 \mathrm{mM}$ Tris- $\mathrm{HCl}(\mathrm{pH} 6 \cdot 8))$ and left at room temperature for $30 \mathrm{~min}$. The mixture was then vortexed and subjected to SDS-PAGE (10\% polyacrylamide). Following electrophoretic separation, protein was transferred to polyvinylidene fluoride membranes. The membranes were then incubated for $1 \mathrm{~h}$ at room temperature in Tris-buffered saline-Tween (TBST) containing 5\% nonfat dried milk ( $\mathrm{pH} 7 \cdot 4$ ). After the blocking step, membranes were incubated overnight in TBST plus 5\% milk containing affinity-purified polyclonal antibody specific for $I \kappa \mathrm{B} \alpha$ (Santa Cruz Biotechnology, Santa Cruz, CA, USA) at a concentration of 1:2000 (note that hepatic I $\kappa \mathrm{B} \alpha$ content was measured in the cytosolic fraction). The same procedure was used to determine serine-phosphorylated and total IRS-1 and IRS-2 in the cytosolic fraction of liver and serinephosphorylated IRS-1 in the soleus muscle and fat. Antibodies against IRS-1, Serine 307 IRS-1, IRS-2 (Upstate, Temecula, CA, USA), and Serine 233 IRS-2 (Labvision, Fremont, CA, USA) were added to the western membranes at dilutions of $1 / 500,1 / 1000,1 / 500$, and $1 / 500$ respectively.

For detection of tyrosine phosphorylation of IRS in the liver, proteins were extracted from rat liver tissue as previously described (Zinker et al. 2002). Liver lysates containing equal amounts of protein $(1 \mathrm{mg})$ were subject to immunoprecipitation overnight at $4{ }^{\circ} \mathrm{C}$ with agarose-conjugated anti-IRS-1 antibody (Upstate) or with anti-IRS-2 antibody (Upstate) followed by 2-h incubation with Protein A/G PLUS-Agarose immunoprecipitation reagent (Santa Cruz) at room temperature. Immune complexes were collected by brief centrifugation $(12000 \mathrm{~g})$ and washed four times with ice-cold PBS. The equivalent amount of protein samples was then resuspended in $1 \times$ Laemmli sample buffer (2\% SDS, $10 \%$ glycerol, $62 \cdot 5 \mathrm{mM}$ Tris (pH 6.8), $0 \cdot 1 \%$ bromophenol blue, and $5 \% \beta$-mercaptoethanol), boiled for $5 \mathrm{~min}$, and separated by SDS-PAGE (10\% polyacrylamide) under reducing conditions, as described above. This was followed by immunoblotting with anti-phosphotyrosine antibody (Santa Cruz; 1/1000 dilution). Note that serine 473-phosphorylated Akt (antibody purchased from Cell Signaling (Beverly, MA, USA); 1/1000 dilution) was measured by western blotting using the same liver lysates that were used for immunoprecipitation of IRS-1 and IRS-2.

After washing thrice with TBST, membranes were incubated for $1 \mathrm{~h}$ at room temperature with horseradish peroxidase-conjugated goat anti-rabbit or anti-mouse IgG (Santa Cruz). The membranes were then washed several times with double-distilled water and developed using ECL reagent (Amersham Biosciences). The bands obtained from immunoblotting were quantified by scanning laser densitometry.

\section{Calculations}

Glucose turnover (rate of appearance of glucose determined with $\left[3-{ }^{3} \mathrm{H}\right]$ glucose) was calculated using Steele's non-steadystate equation (Altszuler et al. 1956), taking into account the extra tracer infused with the glucose infusate (Finegood et al. 1987). In the basal state, the total rate of glucose appearance corresponds to the EGP. During the clamp, EGP was calculated by subtracting the exogenous glucose infusion rate from the total rate of glucose appearance. At steady state, glucose disappearance corresponds to the rate of glucose appearance and at euglycemia glucose disappearance corresponds to tissue glucose utilization as renal glucose clearance is zero. Data are presented as average values of the samples that were taken during the $30 \mathrm{~min}$ preceding the clamp and during the last $30 \mathrm{~min}$ of the clamp.

\section{Statistical analysis}

One-way ANOVA followed by Tukey's post hoc test was used to compare differences between treatment groups for the following parameters: whole body insulin sensitivity, I $\mathrm{I} \mathrm{B} \alpha$ content, serine-phosphorylated IRS-1 and IRS-2, tyrosinephosphorylated IRS-1 and IRS-2, total IRS-1 and IRS-2, and serine 473-phosphorylated Akt. For plasma glucose, FFAs, and insulin as well as EGP and peripheral glucose utilization, we used two-way ANOVA with Tukey's post hoc test in order to compare results between treatment groups and, if necessary, to compare basal and clamp data within each group. Statistical calculations were performed using Statistica software (Statistical Analysis System, Cary, NC, USA). Significance was accepted at a $P<0 \cdot 05$.

\section{Results}

Table 1 shows plasma glucose, FFA, and insulin levels during the basal period and hyperinsulinemic-euglycemic clamp. Plasma glucose levels were not different between treatments during the basal period or the clamp. Plasma FFA levels that were measured during the basal period increased by $\sim 100 \%$ in the $\mathrm{IH}$ and $\mathrm{IH}$ plus SS groups compared with the SAL 


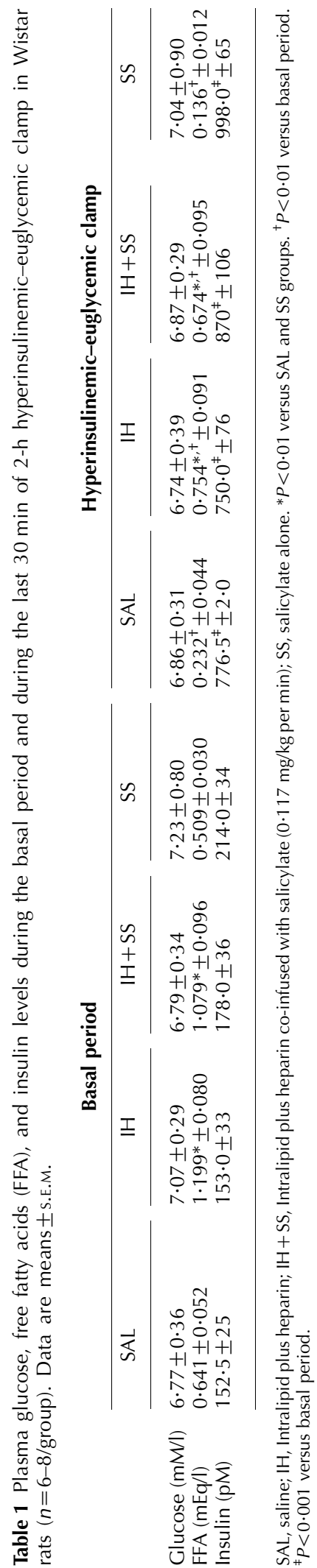

Journal of Endocrinology (2007) 195, 323-331 group due to IH infusion $(P<0 \cdot 01)$. As expected, plasma FFA levels were lower during the hyperinsulinemic clamp than during the basal period in all treatment groups due to the antilipolytic and fat esterification effects of insulin. Plasma insulin levels were not different between groups during the basal period and were markedly elevated during the clamp compared with the basal period in all treatment groups due to insulin infusion.

Glucose infusion rate (GIR) during the last $30 \mathrm{~min}$ of the 2-h hyperinsulinemic-euglycemic clamp is an indication of whole body insulin sensitivity. IH infusion significantly decreased GIR $(P<0 \cdot 01)$ compared with saline infusion (Fig. 1). Salicylate co-infusion with $\mathrm{IH}$ prevented the IH-induced decrease in GIR $(P<0 \cdot 01$ versus IH). Salicylate alone did not have any effect.

During the basal period, EGP is equal to glucose utilization and there was no significant difference between treatment groups (Figs 2A and 3A). During the clamp, we were able to maintain fluctuations in plasma glucose-specific activity from basal at low levels (SAL, +8\%; IH, $-8 \%$; IH + SS, $-21 \%$; SS, $-4 \%$; average percentage difference between basal and clamp), which prevents significant errors in calculation of glucose production (Fisher et al. 1996). IH infusion decreased insulin-stimulated increase in peripheral glucose utilization during the clamp when compared with SAL infusion $(P<0 \cdot 05$; Fig. $2 \mathrm{~B})$. This IH-induced decrease was completely abolished by salicylate co-infusion $(P<0 \cdot 05$ versus $\mathrm{IH})$. The insulin-stimulated increase in peripheral glucose utilization in the SS group did not differ from the SAL group.

Hepatic insulin sensitivity is measured as the capacity of insulin to suppress the EGP from the basal state. In the SAL group, EGP decreased by $37 \%$ from basal during the last 30 min of hyperinsulinemic clamp. However, in IH group, suppression of EGP during clamp was only $7 \%$, which is significantly less than suppression of EGP observed in the SAL group $(P<0 \cdot 05$; Fig. $3 \mathrm{~B})$. Co-infusion of salicylate prevented $\mathrm{IH}$-induced decrease in suppression of EGP during the clamp $(P<0 \cdot 05$ versus IH). Salicylate alone did not have any effect.

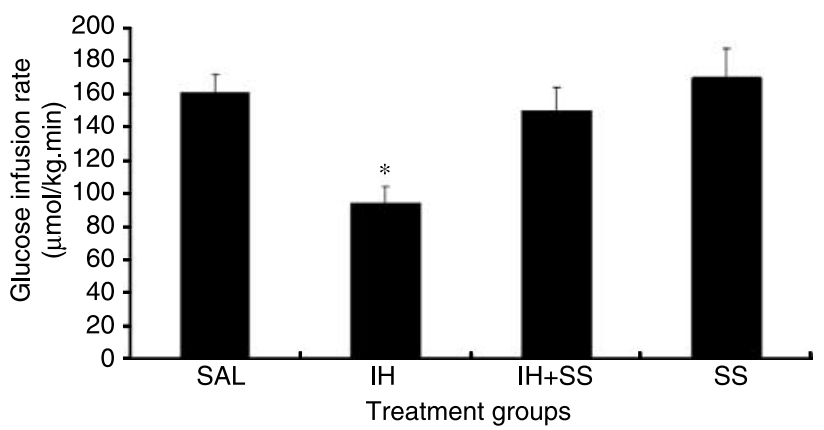

Figure 1 Whole body insulin sensitivity during the last $30 \mathrm{~min}$ of $2-\mathrm{h}$ hyperinsulinemic-euglycemic clamp in Wistar rats ( $n=6-8$ /group). Data are means \pm S.E.M. SAL, saline; $\mathrm{IH}$, Intralipid plus heparin; $\mathrm{IH}+\mathrm{SS}$, Intralipid plus heparin co-infused with salicylate $(0 \cdot 117 \mathrm{mg} / \mathrm{kg}$ per min); SS, salicylate alone. ${ }^{*} P<0 \cdot 01$ versus other groups. 

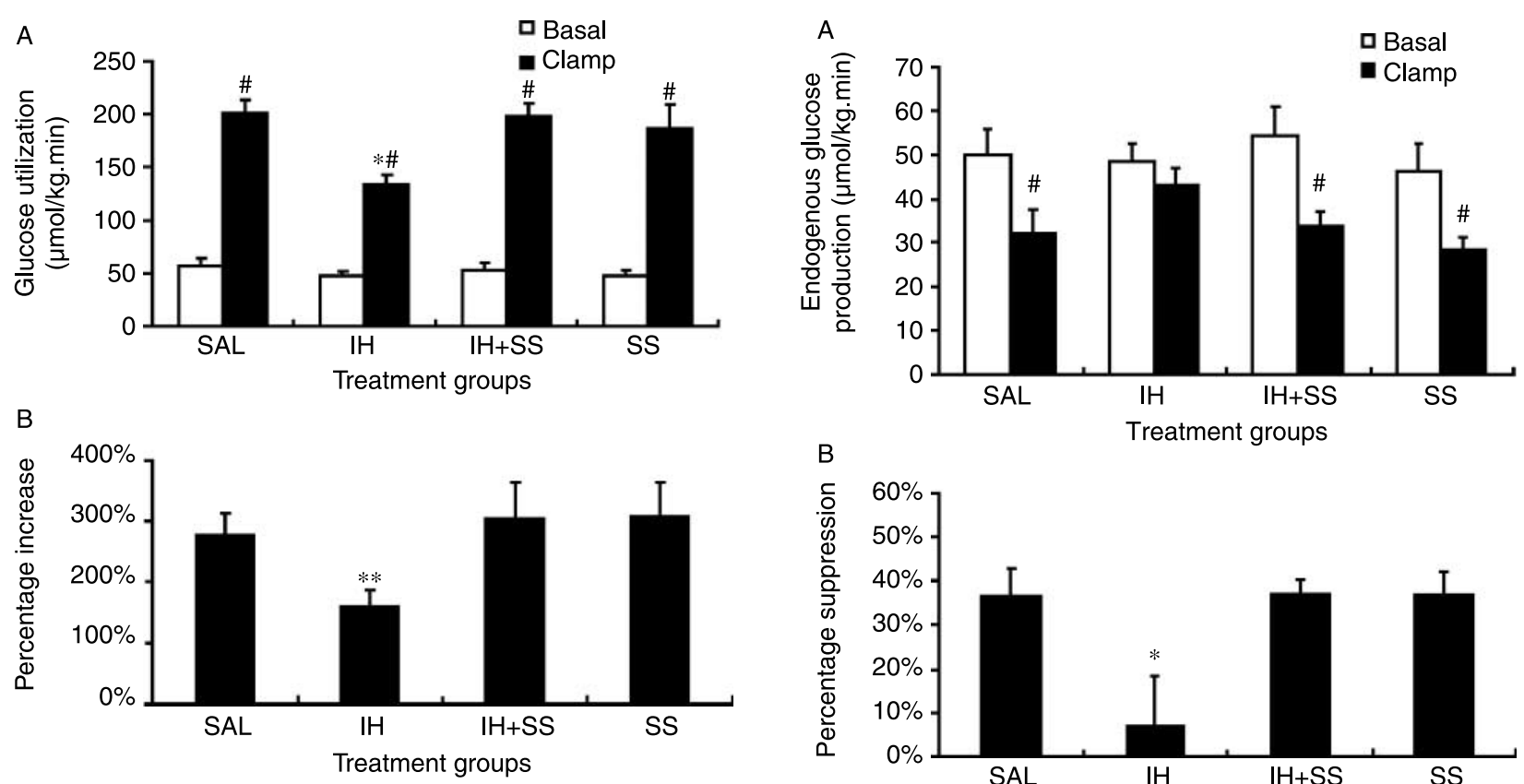

Figure 2 Peripheral glucose utilization in Wistar rats ( $n=6-8$ /group). (A) Effect of $\mathrm{IH}$ and salicylate on peripheral glucose utilization during the basal period and during the last $30 \mathrm{~min}$ of 2-h hyperinsulinemiceuglycemic clamp. (B) Effect of IH and salicylate on insulin-induced percentage increase in peripheral glucose utilization from basal. Data are means \pm s.E.M. SAL, saline; IH, Intralipid plus heparin; IH+SS, Intralipid plus heparin co-infused with salicylate $(0 \cdot 117 \mathrm{mg} / \mathrm{kg}$ per min); SS, salicylate alone. ${ }^{*} P<0 \cdot 01$ versus other groups. ${ }^{* *} P<0 \cdot 05$ versus other groups. ${ }^{\sharp} P<0 \cdot 001$ versus basal period.

In order to assess the effect of salicylate on IKK $\beta$ activity in the liver, we measured hepatic I $\mathrm{B} \alpha$ content (Fig. 4A), which is a marker of IKK $\beta$ activation as I $\kappa \mathrm{B} \alpha$ upon phosphorylation by IKK $\beta$ is targeted for degradation. IH infusion decreased hepatic I $\kappa \mathrm{B} \alpha$ levels $(P<0 \cdot 05)$, which were restored to control levels by salicylate co-infusion. Salicylate alone did not have any effect on hepatic I $\kappa \mathrm{B} \alpha$ levels. IH infusion also decreased $\mathrm{I} \kappa \mathrm{B} \alpha$ content in the soleus muscle $(P<0 \cdot 05)$ and salicylate co-infusion reversed the IH-induced decrease in I $\kappa \mathrm{B} \alpha$ content $(P<0 \cdot 05$ versus $\mathrm{IH}$; Fig. 4B). Again, salicylate alone did not have any effect on soleus muscle I $\kappa \mathrm{B} \alpha$ levels. In adipose tissue, however, IH infusion did not change I $\mathrm{B} \alpha \alpha$ content (Fig. $4 \mathrm{C}$ ).

IKK $\beta$ is known to phosphorylate IRS on serine residues (Gao et al. 2002), thereby decreasing the insulin-induced tyrosine phosphorylation. IH infusion markedly increased serine 307 phosphorylation of IRS-1 (Fig. 5A; $P<0 \cdot 05$ ) and serine 233 phosphorylation of IRS-2 (Fig. 5B; $P<0 \cdot 05$ ) in the liver. Co-infusion of salicylate, however, completely reversed these effects of $\mathrm{IH}(P<0 \cdot 05$ versus $\mathrm{IH})$. IH infusion, however, did not change total IRS-1 and IRS-2 levels (data not shown) and salicylate alone did not have any effect. Furthermore, IH infusion dramatically increased serine 307 phosphorylation of IRS-1 in the soleus muscle $(P<0 \cdot 01)$, which was completely reversed by salicylate co-infusion

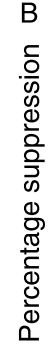

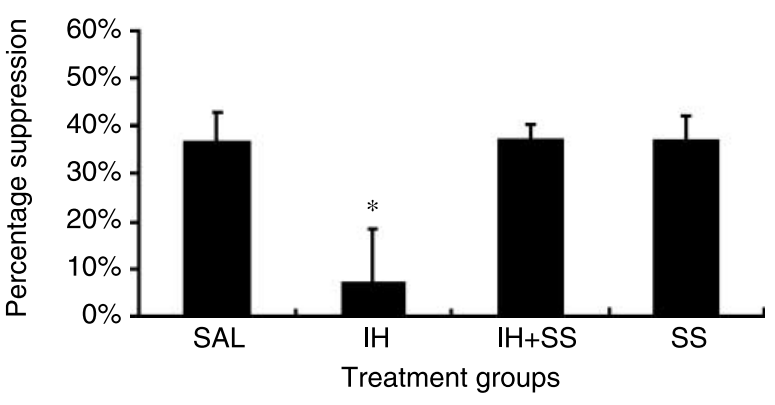

Figure 3 Endogenous glucose production in Wistar rats ( $n=6-8 /$ group). (A) Effect of $\mathrm{IH}$ and salicylate on endogenous glucose production during the basal period and during the last $30 \mathrm{~min}$ of 2-h hyperinsulinemiceuglycemic clamp. (B) Effect of $\mathrm{IH}$ and salicylate on insulin-induced percentage suppression of endogenous glucose production from basal. Data are means \pm S.E.M. SAL, saline; $I H$, Intralipid plus heparin; IH+SS, Intralipid plus heparin co-infused with salicylate $(0 \cdot 117 \mathrm{mg} / \mathrm{kg}$ per min); SS, salicylate alone. ${ }^{*} P<0 \cdot 05$ versus other groups. ${ }^{\sharp} P<0 \cdot 01$ versus basal period.

$(P<0 \cdot 01$ versus IH; Fig. 5C). IH did not alter serine 307 phosphorylation of IRS-1 in the adipose tissue (Fig. 5D).

Tyrosine phosphorylation of IRS by the insulin receptor is a critical step in insulin signaling. Shulman's laboratory has previously shown that short-term lipid infusion impairs tyrosine phosphorylation of IRS-1 in rat skeletal muscle (Kim et al. 2001, 2004b, Yu et al. 2002). In liver, we found that IH infusion decreased tyrosine phosphorylation of IRS-1 (Fig. 6A) and IRS-2 (Fig. 6B; both $P<0.05$ ) and that salicylate co-infusion prevented the $\mathrm{IH}$-induced decreases (both $P<0 \cdot 05$ versus $\mathrm{IH}$ ).

When activated, Akt is phosphorylated at serine 473. IH infusion decreased serine 473-phosphorylated Akt $(P<0 \cdot 05)$ in the liver. This inhibitory effect of IH on Akt was prevented by salicylate co-infusion (Fig. $7 ; P<0 \cdot 05$ versus $\mathrm{IH}$ ).

\section{Discussion}

Recent studies have implicated inflammatory pathways, particularly IKK $\beta /$ nuclear factor $\kappa \mathrm{B}(\mathrm{NF} \kappa \mathrm{B})$ system, in various animal models of insulin resistance (Kim et al. 2001, Yuan et al. 2001, Itani et al. 2002, Arkan et al. 2005, Boden et al. 2005, Cai et al. 2005). However, it is unclear whether 
IKK $\beta$ activation is causally involved in the impairment of hepatic insulin action caused by short-term elevation of FFA. Therefore, the present study in rats was performed to investigate whether inhibition of IKK $\beta$ activity provides protection from FFA-induced hepatic insulin resistance. We demonstrate that treatment with high-dose sodium salicylate completely prevents hepatic insulin resistance caused by short-term lipid infusion in association with prevention of impairment of hepatic insulin signaling.
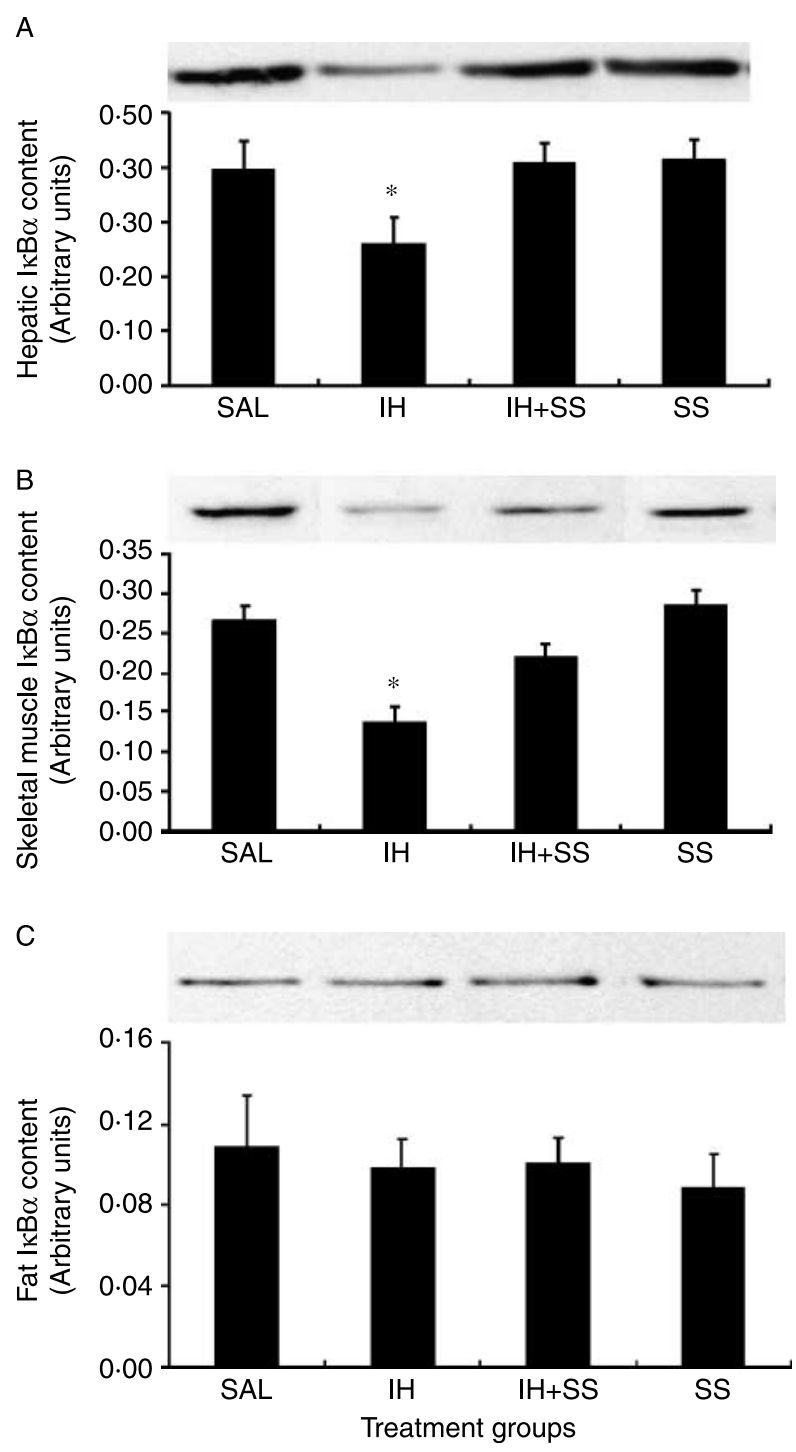

Figure $4 \mathrm{I} \kappa \mathrm{B} \alpha$ content in the liver, skeletal muscle, and fat following 2-h hyperinsulinemic-euglycemic clamp ( $n=6-8$ /group). (A) Effect of $\mathrm{IH}$ and salicylate on hepatic I $\kappa \mathrm{B} \alpha$ content. (B) Effect of $\mathrm{IH}$ and salicylate on $I \kappa B \alpha$ content in the soleus muscle. (C) Effect of $\mathrm{IH}$ and salicylate on $I \kappa B \alpha$ content in fat. A representative image of immunoblots is shown at the top of each graph. Data are means \pm S.E.M. SAL, saline; IH, Intralipid plus heparin; IH + SS, Intralipid plus heparin co-infused with salicylate $(0.117 \mathrm{mg} / \mathrm{kg}$ per $\mathrm{min}) ; \mathrm{SS}$, salicylate alone. ${ }^{*} P<0 \cdot 05$ versus other groups.
As expected, i.v. infusion of IH markedly elevated plasma FFA levels. IH is a triglyceride emulsion containing heparin that is broken down to non-esterified fatty acids and glycerol in vivo by lipoprotein lipase. It is thus possible that glycerol derived from triglycerides by itself affects EGP measured in the present study; however, we have shown in a previous study (Lam et al. 2002) that glycerol infusion (5 mg/kg per min) resulting in plasma glycerol levels similar to that achieved by $7 \mathrm{~h}$ of IH infusion has no effect on EGP when compared with saline infusion either in the basal fasting state or during the hyperinsulinemic-euglycemic clamp.

Infusion rate of exogenous glucose during the clamp is an indication of whole body insulin sensitivity. Numerous studies (Boden 1996, Boden et al. 2001, 2005, Kim et al. 2001, 2004b, Lam et al. 2002, 2003, Yu et al. 2002) have shown that lipid infusion causes whole body insulin resistance and our results are consistent with these studies. The whole body insulin resistance caused by IH infusion was completely reversed with salicylate co-infusion, suggesting that the site of salicylate's effect includes both liver and peripheral tissues. Using infusion of $\left[3-{ }^{3} \mathrm{H}\right]$ tracer, which enabled us to separately assess hepatic and peripheral insulin sensitivity, we show that IH infusion causes both hepatic and peripheral insulin resistance, as indicated by decreases in insulin-induced suppression of EGP from basal and in insulinstimulated peripheral glucose utilization respectively. These results are in agreement with our previous findings (Lam et al. 2002). With salicylate co-infusion, IH-induced insulin resistance in both liver and periphery was completely prevented.

Consistent with the effect of salicylate to prevent IH-induced decrease in peripheral glucose utilization during the clamp, salicylate co-infusion prevented $\mathrm{IH}$-induced decrease in $\mathrm{I} \kappa \mathrm{B} \alpha$ content in parallel with reversal of $\mathrm{IH}$-induced increase in serine 307 phosphorylation of IRS-1 in the skeletal muscle. In the adipose tissue, $\mathrm{IH}$ infusion did not alter $\mathrm{I} \kappa \mathrm{B} \alpha$ content or serine 307 phosphorylation of IRS-1. Although FFA have been shown to decrease glucose uptake in association with the activation of IKK $\beta$ and increased serine 307 phosphorylation of IRS-1 in 3T3L1 adipocytes (Gao et al. 2004), the differences in the experimental models used likely explains the discrepancies in the results. It is noteworthy that, in Kim's study (Kim et al. 2001), short-term lipid infusion did not alter insulin-stimulated glucose uptake in white adipose tissue, which is in keeping with our findings. These results indicate that liver and skeletal muscle were selectively targeted by salicylate and that prevention of FFA-induced peripheral insulin resistance by salicylate is associated with the reversal of serine phosphorylation of IRS-1 in skeletal muscle.

As far as we know, this study is the first to show that salicylate is effective in restoring hepatic insulin sensitivity in a model of acute FFA elevation. While recent studies (Yuan et al. 2001, Arkan et al. 2005) have demonstrated that IKK $\beta$ deficiency is protective against insulin resistance caused by high-fat feeding or genetically induced obesity in rodents, there is an important distinction in the experimental model of insulin resistance used between these studies and our present study. High-fat feeding and genetically induced obesity usually result in chronically elevated FFA levels, which may induce insulin resistance via a 
different mechanism than acute FFA elevation. For instance, in high-fat-fed animals, inhibition of NFKB appears to be sufficient to restore insulin sensitivity without inhibition of IKK $\beta$ activity (Cai et al. 2005), suggesting that the insulin resistance is secondary to transcriptional effects of NFKB, which may not be

A

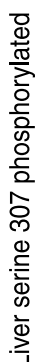

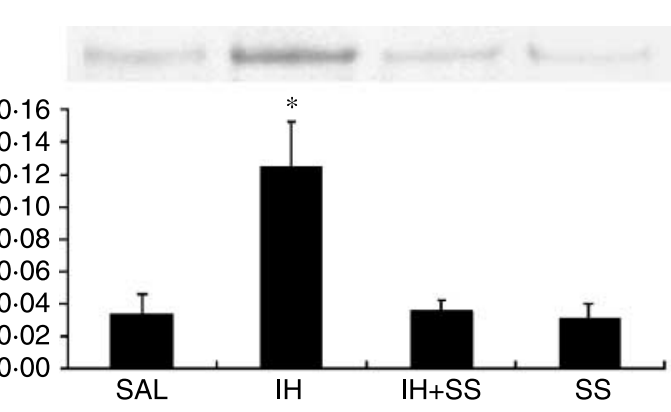

B

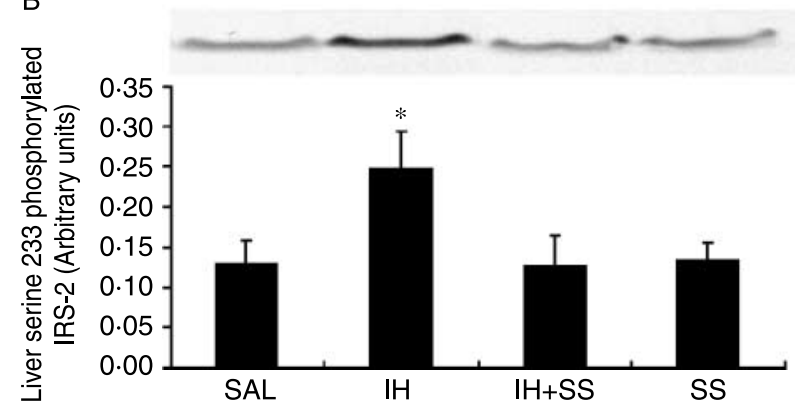

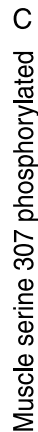
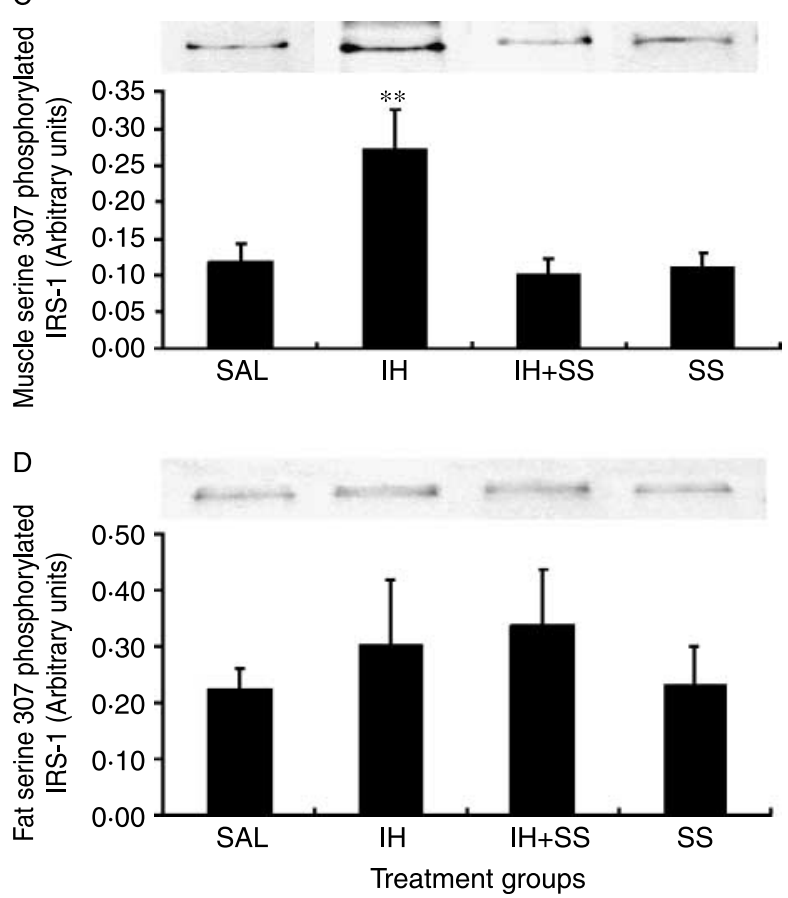

true after short-term lipid infusion. Furthermore, these models are associated with increased release of adipocyte-derived factors other than FFA, such as pro-inflammatory cytokines, tumor necrosis factor $\alpha$ (TNF $\alpha)$, interleukin-1 $\beta$, and interleukin-6 (Hotamisligil \& Spiegelman 1994, Rotter et al. 2003, Kim et al. 2004a, He et al. 2006, Jager et al. 2007) which are known to induce insulin resistance. Accordingly, in these studies, insulin resistance on which IKK $\beta$ inhibition was shown to have a protective effect cannot be attributed only to FFA. Instead, the model of insulin resistance we used is similar to that used by Kim et al. (2001) in their investigation of salicylate's effect on fatinduced insulin resistance in rat skeletal muscle. In this study, however, a high rate of insulin infusion ( $60 \mathrm{pmol} / \mathrm{kg}$ per min) used during the clamp completely suppressed EGP in all groups, potentially masking the effect of salicylate to prevent FFAinduced hepatic insulin resistance. Using a much lower rate of insulin infusion (30 pmol/ $\mathrm{kg}$ per min) and maintaining plasma glucose-specific activity constant to avoid underestimation of glucose production during the clamp (Finegood et al. 1988), we were able to reveal the ability of salicylate to prevent hepatic insulin resistance caused by FFA.

Numerous recent studies (Kim et al. 2001, Arkan et al. 2005, Boden et al. 2005, Cai et al. 2005) have implicated activation of intracellular inflammatory pathway in fat-induced insulin resistance, although it is not clear whether this defect is due to the direct inhibitory effect of IKK $\beta$ on insulin signaling or its indirect effect to promote NFKB-mediated production of proinflammatory cytokines. Since short-term fat infusion can activate IKK $\beta$ (Kim et al. 2001, Boden et al. 2005) and IKK $\beta$ can directly phosphorylate serine residues of IRS-1 (Gao et al. 2002), which prevents tyrosine phosphorylation of IRS and thus insulin signaling (Peraldi \& Spiegelman 1998), it is likely that salicylate prevents fat-induced hepatic insulin resistance directly through prevention of IKK $\beta$ activity. In support of this notion, we found that salicylate completely prevents $\mathrm{IH}$-induced decrease in hepatic I $\mathrm{B} \boldsymbol{\alpha} \alpha$ content, which indicates increased IKK $\beta$ activity as I $\mathrm{B} \alpha$ upon phosphorylation by IKK $\beta$ is targeted for degradation. Interestingly, salicylate alone had no effect on hepatic I $\mathrm{B} \alpha$ content in the absence of elevated FFA, presumably because the dose of salicylate we used was not sufficiently high to suppress IKK $\beta$ activity beyond its baseline levels.

The preventive effect of salicylate on IH-induced IKK $\beta$ activation occurred in association with prevention of $\mathrm{IH}$-induced increase in serine 307 phosphorylation and decrease in tyrosine

Figure 5 Serine phosphorylation of the insulin receptor substrate (IRS) in the liver, skeletal muscle, and fat following 2-h hyperinsulinemiceuglycemic clamp ( $n=6-8 /$ group). (A) Effect of IH and salicylate on serine 307 phosphorylation of IRS- 1 in the liver. (B) Effect of IH and salicylate on serine 233 phosphorylation of IRS-2 in the liver. (C) Effect of $\mathrm{IH}$ and salicylate on serine 307 phosphorylation of IRS- 1 in the soleus muscle. (D) Effect of IH and salicylate on serine 307 phosphorylation of IRS-1 in fat. A representative image of immunoblots is shown at the top of each graph. Data are means \pm s.E.M. SAL, saline; IH, Intralipid plus heparin; IH+SS, Intralipid plus heparin co-infused with salicylate $(0 \cdot 117 \mathrm{mg} / \mathrm{kg}$ per $\mathrm{min}) ; \mathrm{SS}$, salicylate alone. $* P<0 \cdot 05$ versus other groups. ${ }^{* *} P<0 \cdot 01$ versus other groups. 


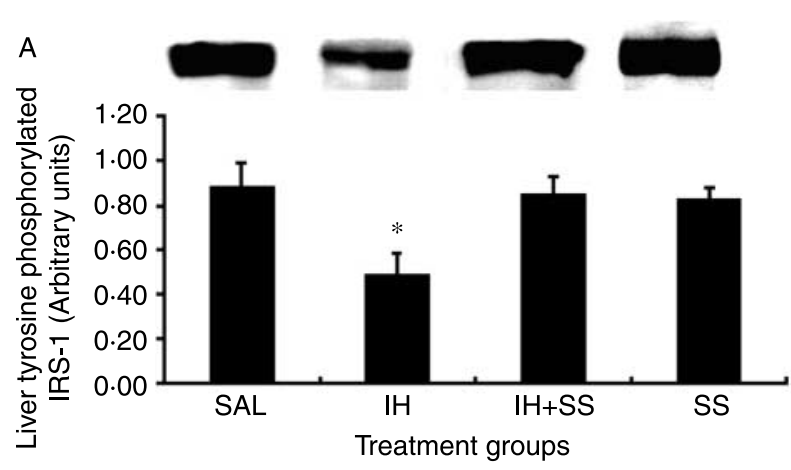

tyrosine phosphorylation of IRS-1 and thus impedes insulin signaling (Aguirre et al. 2000). It was recently shown that FFA cause insulin resistance through IKK $\beta$ - and JNK1-medicated serine (307) phosphorylation of IRS-1 in 3T3-L1 adipocytes (Gao et al. 2004). Furthermore, serine 307 phosphorylation of IRS-1 caused by short-term fat infusion was associated with decreased tyrosine phosphorylation of IRS-1 and impairment of insulin signaling in rat skeletal muscle, although the serine kinase responsible was not identified (Yu et al. 2002). Our results show that salicylate also prevents IH-induced increase in serine 233 phosphorylation of IRS-2 (Fig. 5B), which has been linked to insulin resistance (Scioscia et al. 2006). Although it is still unknown whether serine 233 phosphorylation interferes with tyrosine phosphorylation of IRS-2, our finding of concomitant decrease in tyrosine phosphorylation of IRS-2 indicates that these processes may be linked.

In addition to defects in tyrosine phosphorylation of IRS, IH infusion was found to reduce serine 473 phosphorylation of Akt, which was prevented with salicylate co-infusion. Taken together, our results suggest that the effect of salicylate to restore hepatic insulin sensitivity is closely associated with its reversal of fat-induced impairment of hepatic insulin signaling.

Although our findings confirm the ability of high-dose salicylate to inhibit IKK $\beta$, we cannot exclude the possibility that salicylate prevents IKK $\beta$-induced transcription of various proinflammatory cytokines, thereby inhibiting their autocrine effect to impair hepatic insulin signaling. However, relatively short exposure to elevated FFA may preclude IKK $\beta$-induced transcription of pro-inflammatory genes. Furthermore, while salicylate is a relatively weak inhibitor of cyclooxygenase (COX) due to a lack of acetyl group that is required for deactivation of the enzyme, it is nonetheless possible that salicylate had some effect in inhibiting COX-mediated prostaglandin production. However, given that neither a treatment with non-steroidal anti-inflammatory drugs, which are robust inhibitors of COX, nor COX deficiency prevented insulin resistance in Fao hepatoma cells and in obese mice (Yuan et al. 2001) respectively, it is unlikely that potentially inhibitory effect of salicylate on prostaglandin played a role in the present study.

In summary, the present study demonstrates that 1) a highdose treatment with sodium salicylate prevents hepatic insulin resistance caused by short-term elevation of plasma FFA and 2) the effect of salicylate to restore hepatic insulin sensitivity occurs in association with prevention of FFA-induced hepatic IKK $\beta$ activation and corresponding impairment of hepatic insulin signaling. The findings of this study suggest that IKK $\beta$ is a causal mediator of hepatic insulin resistance induced by acutely elevated plasma FFA. Therefore, hepatic IKK $\beta$ represents a potential therapeutic target to prevent or treat fat-induced hepatic insulin resistance and associated diseases.

\section{Acknowledgements}

Figure 7 Serine 473 phosphorylation of Akt in the liver following 2-h hyperinsulinemic-euglycemic clamp ( $n=6-8 /$ group). A representative image of immunoblots is shown at the top of the graph. Data are means \pm S.E.M. SAL, saline; IH, Intralipid plus heparin; $\mathrm{IH}+\mathrm{SS}$, Intralipid plus heparin co-infused with salicylate $(0 \cdot 117 \mathrm{mg} / \mathrm{kg}$ per min); SS, salicylate alone. ${ }^{*} P<0 \cdot 05$ versus other groups.

The authors would like to thank Loretta Lam for her excellent technical support. This study was funded by a research grant 
to A G from Canadian Diabetes Association. Partial support was provided by grants to A $G$ from Canadian Institutes of Health Research and the Heart and Stroke Foundation of Canada. E P was supported by a Banting and Best Diabetes Centre NovoNordisk Studentship and an Ontario Graduate Scholarship in Science and Technology. A I O was funded by Ontario Graduate Scholarship. VW was funded by a Canadian Institutes of Health Research Doctoral Scholarship and a Banting and Best Diabetes Centre Novo Nordisk Studentship. The authors declare that there is no conflict of interest with the source of funding for the present study that would prejudice its impartiality.

\section{References}

Aguirre V, Uchida T, Yenush L, Davis R \& White MF 2000 The c-Jun $\mathrm{NH}(2)$-terminal kinase promotes insulin resistance during association with insulin receptor substrate-1 and phosphorylation of Ser(307). Journal of Biological Chemistry 275 9047-9054.

Altszuler N, De Bodo RC, Steele R \& Wall JS 1956 Measurement of size and turnover rate of body glucose pool by the isotope dilution method. American Journal of Physiology 187 15-24.

Arkan MC, Hevener AL, Greten FR, Maeda S, Li ZW, Long JM, WynshawBoris A, Poli G, Olefsky J \& Karin M 2005 IKK-beta links inflammation to obesity-induced insulin resistance. Nature Medicine 11 191-198.

Beard KM, Lu H, Ho K \& Fantus IG 2006 Bradykinin augments insulinstimulated glucose transport in rat adipocytes via endothelial nitric oxide synthase-mediated inhibition of Jun NH2-terminal kinase. Diabetes $\mathbf{5 5}$ $2678-2687$.

Birnbaum MJ 2001 Turning down insulin signaling. Journal of Clinical Investigation 108 655-659.

Boden G 1996 Fatty acids and insulin resistance. Diabetes Care 19 394-395.

Boden G, Lebed B, Schatz M, Homko C \& Lemieux S 2001 Effects of acute changes of plasma free fatty acids on intramyocellular fat content and insulin resistance in healthy subjects. Diabetes 50 1612-1617.

Boden G, She P, Mozzoli M, Cheung P, Gumireddy K, Reddy P, Xiang X, Luo Z \& Ruderman N 2005 Free fatty acids produce insulin resistance and activate the proinflammatory nuclear factor- $\mathrm{KB}$ pathway in rat liver. Diabetes 54 3458-3465.

Cai D, Yuan M, Frantz DF, Melendez PA, Hansen L, Lee J \& Shoelson SE 2005 Local and systemic insulin resistance resulting from hepatic activation of IKK-beta and NF-KB. Nature Medicine 11 183-190.

Finegood DT, Bergman RN \& Vranic M 1987 Estimation of endogenous glucose production during hyperinsulinemic-euglycemic glucose clamps. Comparison of unlabeled and labeled exogenous glucose infusates. Diabetes 36 914-924.

Finegood DT, Bergman RN \& Vranic M 1988 Modeling error and apparent isotope discrimination confound estimation of endogenous glucose production during euglycemic glucose clamps. Diabetes 37 1025-1034.

Fisher SJ, Shi ZQ, Lickley HL, Efendic S, Vranic M \& Giacca A 1996 A moderate decline in specific activity does not lead to an underestimation of hepatic glucose production during a glucose clamp. Metabolism 45 587-593.

Gao Z, Hwang D, Bataille F, Lefevre M, York D, Quon MJ \& Ye J 2002 Serine phosphorylation of insulin receptor substrate 1 by inhibitor $\mathrm{\kappa B}$ kinase complex. Journal of Biological Chemistry 277 48115-48121.

Gao Z, Zhang X, Zuberi A, Hwang D, Quon MJ, Lefevre M \& Ye J 2004 Inhibition of insulin sensitivity by free fatty acids requires activation of multiple serine kinases in 3T3-L1 adipocytes. Molecular Endocrinology 18 2024-2034.

He J, Usui I, Ishizuka K, Kanatani Y, Hiratani K, Iwata M, Bukhari A, Haruta T, Sasaoka T \& Kobayashi M 2006 Interleukin-1alpha inhibits insulin signaling with phosphorylating insulin receptor substrate- 1 on serine residues in 3T3-L1 adipocytes. Molecular Endocrinology 20 114-124.

Hotamisligil GS \& Spiegelman BM 1994 Tumor necrosis factor alpha: a key component of the obesity-diabetes link. Diabetes 43 1271-1278.
Itani SI, Zhou Q, Pories WJ, Macdonald KG \& Dohm GL 2000 Involvement of protein kinase $\mathrm{C}$ in human skeletal muscle insulin resistance and obesity. Diabetes 49 1353-1358.

Itani SI, Ruderman NB, Schmieder F \& Boden G 2002 Lipid-induced insulin resistance in human muscle is associated with changes in diacylglycerol, protein kinase C, and IкB-alpha. Diabetes 51 2005-2011.

Jager J, Gremeaux T, Cormont M, Marchand-Brustel Y \& Tanti JF 2007 Interleukin- $1 \beta$-induced insulin resistance in adipocytes through downregulation of insulin receptor substrate-1 expression. Endocrinology 148 241-251.

Kim JK, Kim YJ, Fillmore JJ, Chen Y, Moore I, Lee J, Yuan M, Li ZW, Karin M, Perret $\mathrm{P}$ et al. 2001 Prevention of fat-induced insulin resistance by salicylate. Journal of Clinical Investigation 108 437-446.

Kim HJ, Higashimori T, Park SY, Choi H, Dong J, Kim YJ, Noh HL, Cho YR, Cline G, Kim YB et al. 2004a Differential effects of interleukin-6 and -10 on skeletal muscle and liver insulin action in vivo. Diabetes 53 1060-1067.

Kim JK, Fillmore JJ, Sunshine MJ, Albrecht B, Higashimori T, Kim DW, Liu ZX, Soos TJ, Cline GW, O'Brien WR et al. 2004b PKC-theta knockout mice are protected from fat-induced insulin resistance. Journal of Clinical Investigation $\mathbf{1 1 4}$ 823-827.

Lam TK, Yoshii H, Haber CA, Bogdanovic E, Lam L, Fantus IG \& Giacca A 2002 Free fatty acid-induced hepatic insulin resistance: a potential role for protein kinase C-delta. American Journal of Physiology. Endocrinology and Metabolism 283 E682-E691.

Lam TK, van de Werve G \& Giacca A 2003 Free fatty acids increase basal hepatic glucose production and induce hepatic insulin resistance at different sites. American Journal of Physiology. Endocrinology and Metabolism 284 E281-E290.

Peraldi P \& Spiegelman B 1998 TNF-alpha and insulin resistance: summary and future prospects. Molecular and Cellular Biochemistry 182 169-175.

Roden M, Price TB, Perseghin G, Petersen KF, Rothman DL, Cline GW \& Shulman GI 1996 Mechanism of free fatty acid-induced insulin resistance in humans. Journal of Clinical Investigation 97 2859-2865.

Rotter V, Nagaev I \& Smith U 2003 Interleukin-6 (IL-6) induces insulin resistance in 3T3-L1 adipocytes and is, like IL-8 and tumor necrosis factoralpha, overexpressed in human fat cells from insulin-resistant subjects. Journal of Biological Chemistry 278 45777-45784.

Scioscia M, Gumaa K, Kunjara S, Paine MA, Selvaggi LE, Rodeck CH \& Rademacher TW 2006 Insulin resistance in human preeclamptic placenta is mediated by serine phosphorylation of insulin receptor substrate- 1 and -2 . Journal of Clinical Endocrinology and Metabolism 91 709-717.

Solinas G, Naugler W, Galimi F, Lee MS \& Karin M 2006 Saturated fatty acids inhibit induction of insulin gene transcription by JNK-mediated phosphorylation of insulin-receptor substrates. PNAS 103 16454-16459.

Wong V, Szeto L, Uffelman K, Fantus IG \& Lewis GF 2006 Enhancement of muscle glucose uptake by the vasopeptidase inhibitor, omapatrilat, is independent of insulin signaling and the AMP kinase pathway. Journal of Endocrinology 190 441-450.

Yu C, Chen Y, Cline GW, Zhang D, Zong H, Wang Y, Bergeron R, Kim JK, Cushman SW, Cooney GJ et al. 2002 Mechanism by which fatty acids inhibit insulin activation of insulin receptor substrate-1 (IRS-1)-associated phosphatidylinositol 3-kinase activity in muscle. Journal of Biological Chemistry 277 50230-50236.

Yuan M, Konstantopoulos N, Lee J, Hansen L, Li ZW, Karin M \& Shoelson SE 2001 Reversal of obesity- and diet-induced insulin resistance with salicylates or targeted disruption of Ikkbeta. Science 293 1673-1677.

Zinker BA, Rondinone CM, Trevillyan JM, Gum RJ, Clampit JE, Waring JF, Xie N, Wilcox D, Jacobson P, Frost L et al. 2002 PTP1B, antisense oligonucleotide lowers PTP1B protein, normalizes blood glucose, and improves insulin sensitivity in diabetic mice. PNAS 99 11357-11362.

Received in final form 6 August 2007

Accepted 30 August 2007

Made available online as an Accepted Preprint 30 August 2007 